\title{
Effect of Advertisement on Buying Behavior of OTC Medicinesin Nepalese Context
}

\author{
Pankaj Kumar Tiwari \\ PhD Scholar, Dr. KN Modi University, Newai, Rajasthan, India \\ Email: omnipankaj@gmail.com
}

\begin{abstract}
Buying of OTC medicines is the self-medication practice. From the very ancient period, people used different types of herbs for the treatment of their health problems. In the changing practice of human life, people modern treatment took over. Advertisement has become the fastest marketing communication to disseminate the message in the global society. In this connection, the study is going to identify the effect of advertisement on buying behavior of OTC medicines in Nepalese context. The study was based on the descriptive design. Data was collected from the 400 OTC consumers by using the structured questionnaire survey. Systematic random sampling technique was used to select the respondents. The study found that $41.2 \%$ people were aware through the advertisement of OTC medicines whereas only $32 \%$ had purchased the OTC medicine after watching the advertisement. Similarly, only $14.8 \%$ reported that they were influenced by the advertisement and $46 \%$ said that advertisement of OTC medicine had positive effect on the people as people are well informed regarding the medicines through such advertisements. It helped to sensitize the people. Study found that there was positive contribution of advertisement to disseminate the message but not so effective to change the buying behavior of consumer. Only 6.8\%people believe in the advertisement done through the television or print media. People mostly rely on the recommendation of doctors or pharmacists in Nepalese context. Thus, pharmaceutical companies can use the pharmacists for the effective advertisement and sales of OTC medicines.
\end{abstract}

\section{KEYWORDS}

Advertisement, buying behavior, effect, OTC medicines

\section{INTRODUCTION}

Choices of people are different based on different cultural context. People seek the information of their choice from various sources; either formal or informal. This is the age of communication technology; people receive the message halfway through the world within seconds. In this connection, advertisement of any goods and services through online and print media reaches the people around the globe at a very fast pace. It is said that 'health is wealth', so health awareness becomes the first priority of any person of all culture. People frequent different health clinics to seek the treatment for their health problem. It is the common practice of people that they visit medical hall to purchase OTC medicines for their common health problems. Either people ask for the medicine stating their health problem or directly the name of the medicine before purchasing any medicine. 'OTC Drugs' means drugs legally allowed to be sold 'Over the Counter', 
i.e. without the prescription of a Registered Medical Practitioner. In India, though the phrase has no legal recognition, all the drugs that are not included in the list of 'prescription drugs' are considered as non-prescription drugs (or OTC drugs) (Bhangale, 8-10 April, 2007, p. 397; Khan, Gupta, Goswami, Bihari, \& Verma, 2013, p. 72). Producers use the online media; television, radio, internet or print media; newspaper, magazine, poster, pamphlet, hording-board to advertise their medicines.

Advertising in its simplest form means "public announcement". Advertising as described by the American Marketing Association, Chicago is basically "any paid form of non-personal presentation of ideas, goods and services by an identified sponsor." This definition in itself states that advertising is mostly a form of persuasive communication with the audience. Further, it is also clear from the definition that advertising is basically one-sided information where information flows from the part of the advertiser (sender) to the public (receiver) (Dhar, 2011, p. 1). Advertising means the creative communication with the consumer. As a form of communication, advertising serves the purpose of a guide to buying in which the intended message is delivered to masses through various media (R. Bakhshi, 2010, p. 185).People collect the message of different goods and services from the advertisement and physically visit the concerned retail outlets to purchase such goods. The main objective of advertisement is to inform and sensitize the people regarding the available goods and services. So, in this connection, the study is going to identify the effect of advertisement on buying behavior of OTC medicines in the Nepalese context.

\section{METHOD}

The study is based on the descriptive study design because the study is going to identify the status of effect of advertisement on buying behavior of OTC medicines among the Nepalese consumers. The data were collected from 400 consumers by using the structured questionnaires. For the true representation of Nepalese context, five development regions of Nepal: Eastern, Central, Western, Mid-western and Far-western Region has been covered by the study. Systematic random sampling technique was used to select the customers. During the course of study, retail pharmacies (medical shops) were visisted and the customers frequenting the pharmacies for the OTC medicine were interviewed in every two hour interval from the starting of $1^{\text {st }}$ interview. Mostly the data were collected during morning and evening time when most people visit the retail pharmacy to purchase the OTC medicines. Written consent was taken from the each respondent to ensure the confidentiality of respondents. The data was analyzed through the statistical software (SPSS) and data are presented in the tabular/diagrammatic forms.

\section{RESULTS AND DISCUSSION}

\section{Awareness of OTC medicines through advertisement}

The data presented in the figure no. 1 shows that in total $41.2 \%$ consumers reported that they had been aware about the OTC medicines from the advertisement. Second highest percentage $(30.2 \%)$ 
reported that they did not know about advertisement, similarly $27.8 \%$ reported that the advertisements had no significant effect on their awareness level. The level of awareness was found less than $50 \%$ from the advertisement of OTC medicines which could be said the less effect of advertisement of OTC medicines.

Figure 1: Awareness of OTC medicines through advertisement

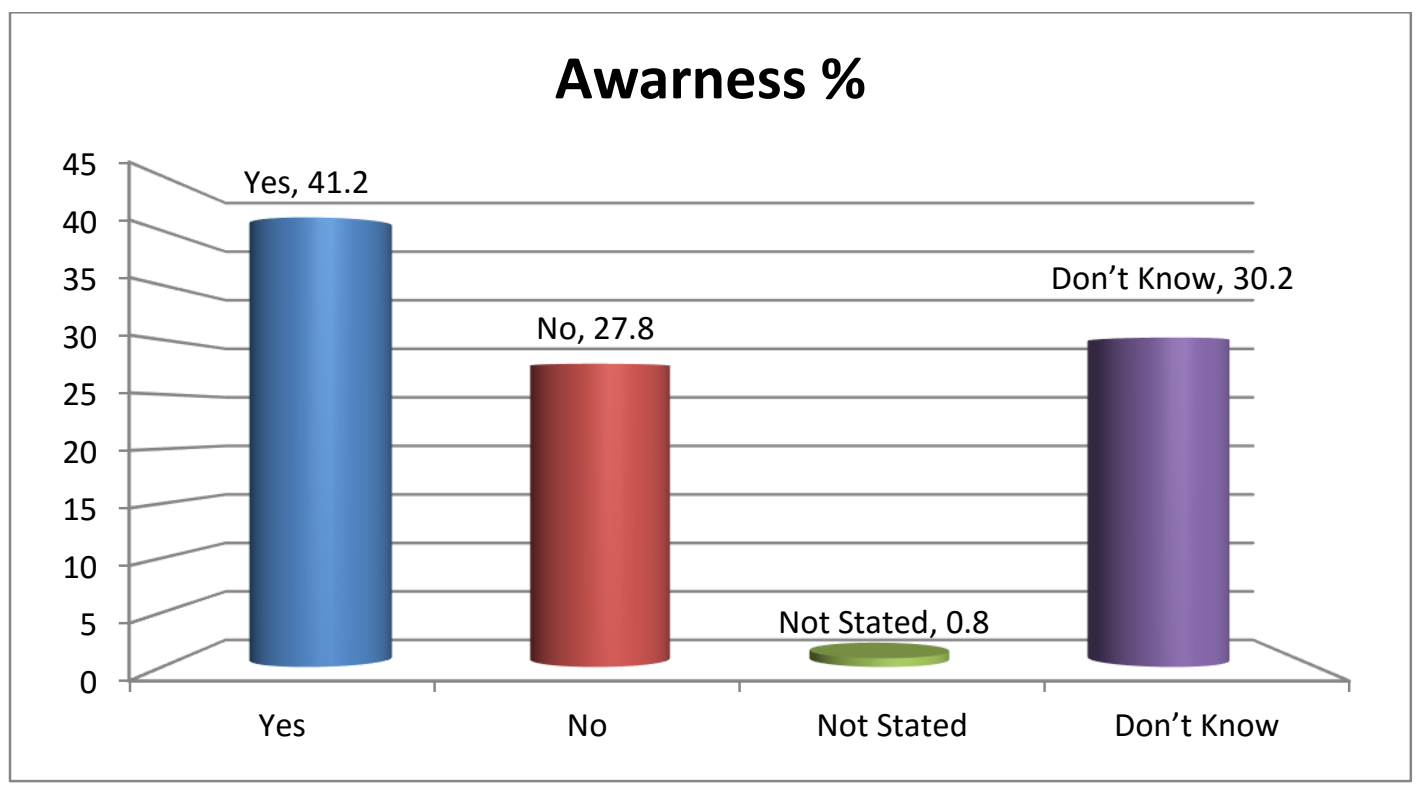

Source: Field survey, 2015

Advertising is one of the most important cultural sign systems that reflect and shape our lives. It is an inevitable part of anyone's life. Even if one does not read the newspaper or watch television it is impossible to escape the advertising images that pervade our surroundings, via hoardings, wall paintings, pop-up material or even the radio, cutting across all media but limited to none (Sawant, 2012 , p. 56). It was also observed that there was less number of advertisements of OTC medicines from the Nepalese TV channels in comparison to Indian channels. It may be the reason that those among the Nepalese customers less than 50\% were aware about the medicines through the advertisement.

The World Self-Medication Industry said that People are cautious and careful when they use OTCs, and are not prompted to an over reliance as a result of advertising. Further, most people in all of the nations surveyed read the label carefully before taking an OTC medicine at the first time (The World Self-Medication Industry, 2007).

\section{Buy medicines by seeing Advertisement}


This is the fashion that many people purchase the luxurious goods and need based goods by seeing the advertisements. Now a days, online marketing system is also available so that there is no problem to purchase any items; supplier can deliver the goods in given address. In this connection, the respondents were asked about the influence of the advertisements on their buying behavior. The data presented in figure no. 2 shows that in total only $32.26 \%$ said that they had purchased the medicine after viewing the advertisement whereas $60.44 \%$ said that they had never purchased such medicine only on the basis of the advertisements.

Figure 2: Buy medicines by seeing Advertisement

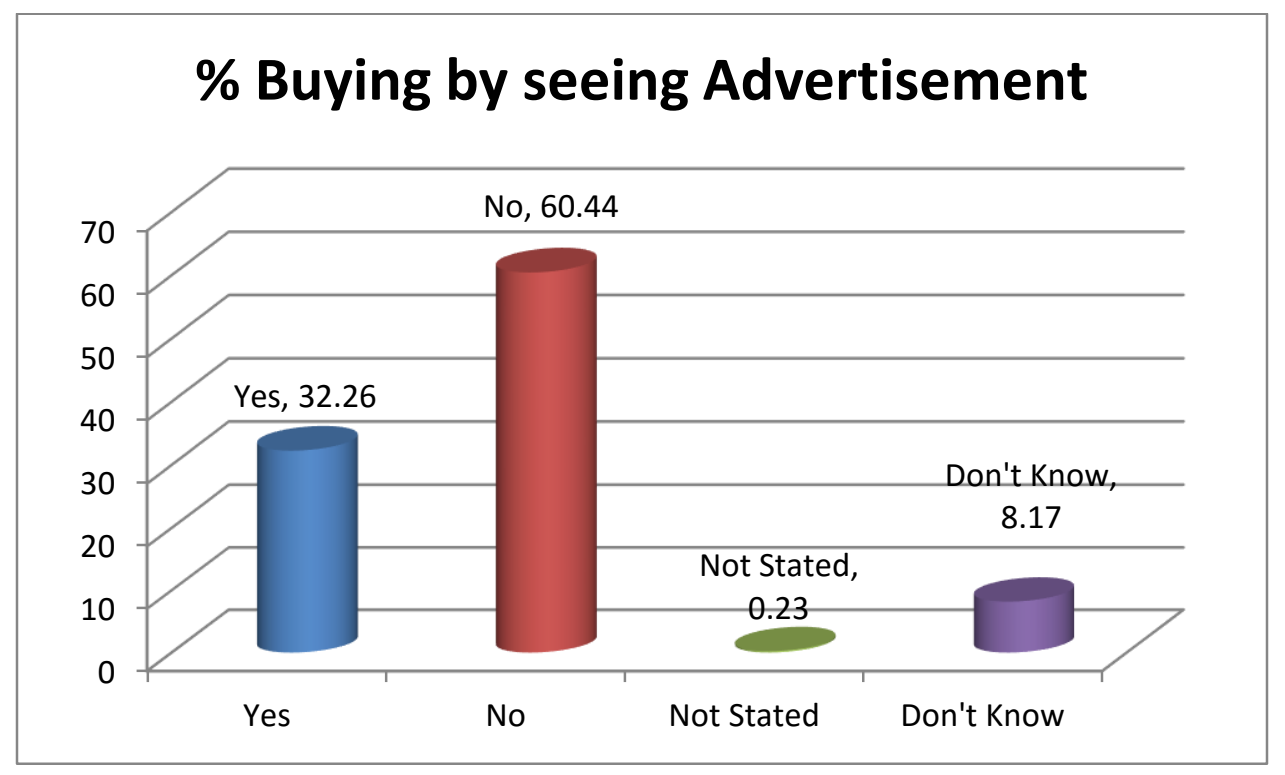

Source: Field survey, 2015

\section{Name of OTC medicines purchased by seeing advertisement}

During the study respondents were asked regarding the brand name of the OTC medicines they purchased after seeing the advertisement of medicines. The main objective of the advisement is to attract people's attention towards the brand name of the product so that the customers recall it while purchasing, and eventually the sale of products will increase. Name of the top 10 medicines brands presented in the figure no. 3 showed the chosen brand while purchasing the OTC medicine by the customers. 
ISSN: 2362-1303 (Paper) | elSSN: 2362-1311(Online)

Figure 3: Name of OTC medicinespurchased by seeing advertisement

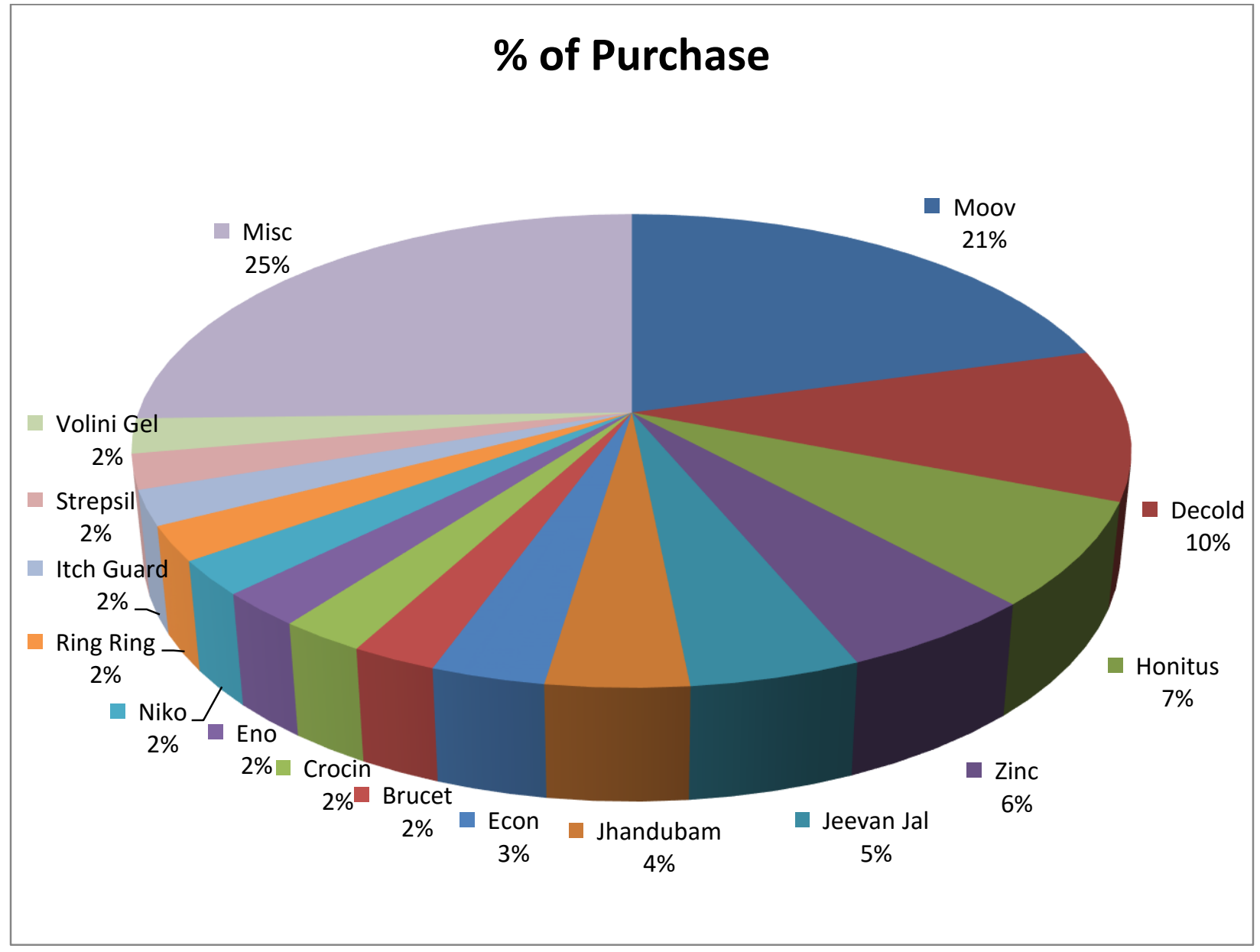

Source: Field survey, 2015

The data shows that in total 128 people purchased the OTC medicines after viewing advertisement of medicines. 'Moov' was the top brand recalled by the customers while purchasing. $20 \%$ of the respondents reported that they purchase Moov. It is a muscle relaxant ointment locally applied for pain and inflammation. It has a wide coverage in the Indian TV advertisement. 'De-cold' was considered by most of the respondents after moov, $10 \%$ of the respondents purchase De-cold after viewing its advertisement. It is a medicine for common cold, cold and flu, headache etc. De-cold is advertised by many Indian TV channels. 'Honitous' was purchased by $7 \%$ of the respondents; it is a cough preparation, advertised in Nepalese and Indian TV channels. 'Zinc' and 'Jeevan Jal' 
were considered as fourth popular in terms of their preference, $5 \%$ of the respondents purchased Zinc and Jeevan Jal. Zinc has a massive promotional campaign by Government of Nepal under Baby Zinc scheme. Surprisingly, Jeevan Jal was not available during the period of survey. It shows strong brand recognition; Jeevan Jal is Nepal Drug Limited product and has not been available since many years.

'Jhandubalm'was purchased by $4 \%$ of the respondents, as the brand is highly promoted by Indian TV. Econ (emergency contraceptive pill) was purchased by $3 \%$ of the customers. Whereas, Brucet, Crocin, Eno, Niko, Ring-Ring, Itch guard, Volini Gel and Strepsils each were purchased by $2 \%$ of the customers. $20 \%$ of the respondents had purchased miscellaneous products. It was evident that the products advertised in the television had quite an impact on the purchase decisions of the customers of OTC medicines.

\section{Medicine purchased for different disease symptoms by seeing advertisement}

Impact of advertisement of OTC medicines on purchasing behavior was measured by asking the respondents about their buying behaviour as per the symptoms. People were aware of the names of medicines and its use on the specific health problem. Consumers' were aware that they could purchase the different types of medicine for their health problem so that they visited the retail pharmacy and asked medicine as per the symptoms.

Figure 4: Medicine purchased for disease symptoms problem by seeing advertisement

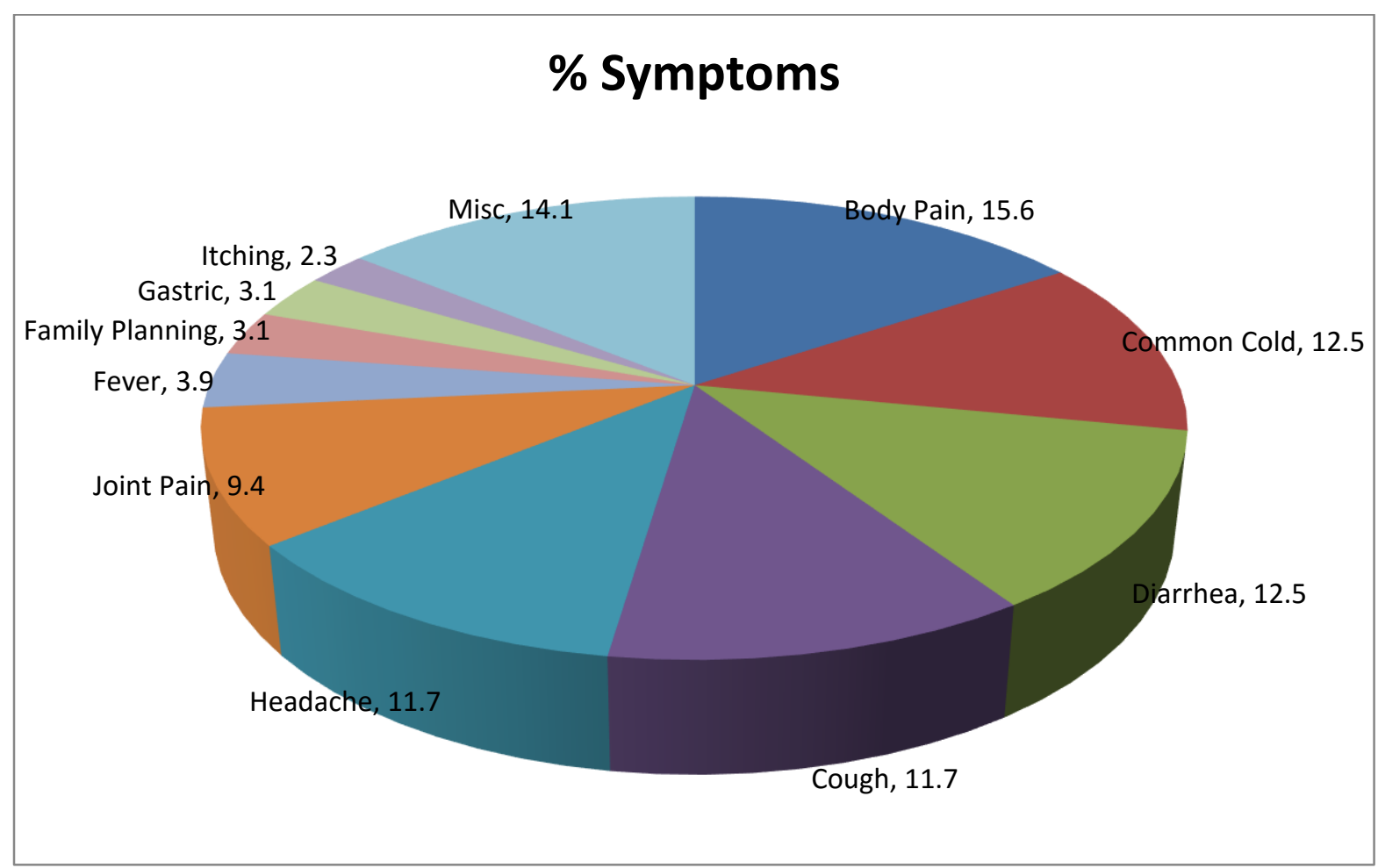


Source: Field survey, 2015

Out of 128 respondents, $15.6 \%$ people purchased the medicine for the body pain, $12.5 \%$ people purchased for the common cold \& Diarrhea, $11.7 \%$ people purchased for Cough and Headache, 9.4\% people purchased OTC medicines for joint pain symptom. 3.9\% of the respondents purchased OTC medicines for fever and $3.1 \%$ people purchased family planning pills and gastric, whereas, $2.3 \%$ purchased for skin itching. And rest $14.1 \%$ of the respondents purchased OTC medicines for different symptoms. The common ailments associated with pain, cold, diarrhea, cough and headache are the mostly shouted symptoms for purchasing of OTC medicines.

\section{Faithful medium of advertisement}

The customers of OTC medicines were asked about the faithful medium of advertisement of medicines. It is observed in the market that different medium; online media, print media, from the informal channels are being used to advertise the medicines.

The data presented in the figure no. 5 shows that in total $75.2 \%$ said that advertisements done by medical hall was more trustworthy because the medical person who was more familiar with the medicines was involved. Similarly, $4 \%$ said that advertisements on Television was more trustable followed by $2.8 \%$ who trusted on advertisement through magazine, $6.5 \%$ said that medicines referred by the family members was more trustable, $5 \%$ believed on friends' referral and $4.5 \%$ reported other medium such as health workers, medical representatives and internet.

Figure 5: Faithful medium of advertisement

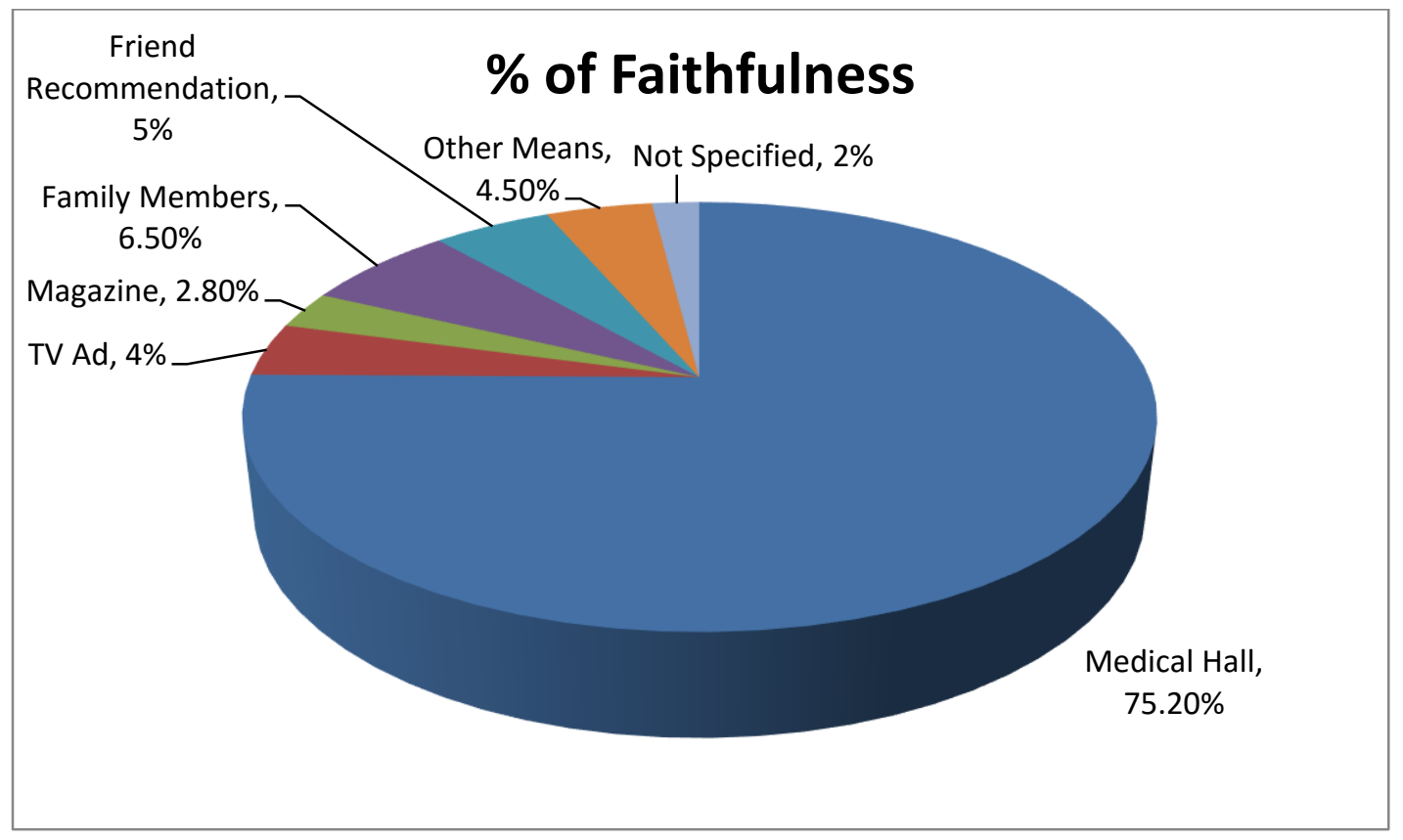

Source: Field survey, 2015 
ISSN: 2362-1303 (Paper) | elSSN: 2362-1311(Online)

JOURNAL OF ADVANCED ACADEMIC RESEARCH (JAAR)

Jan 2016

The data reported that customers were aware in relation to gather the knowledge of medicine because data very clearly shows that people believed on the recommendations made by medical hall than any other. Majority of the respondents believe Medical institutions and medical persons are the authorized institutions, who hold the responsibility and knowledge of product and distribution of such OTC medicines.

\section{Level of influence due of the advertisement of OTC medicines}

The customers of OTC medicines were asked about the level of influence advertisements of OTC medicines had on them. Advertisement is one of the tools to influence the buying behavior of customers. It uses artists, players, social activists and other celebrities to publicize the goods and products in the market.

Table 1: Level of influence due to the advertisement of OTC medicines

\begin{tabular}{|l|c|c|c|c|c|c|}
\hline \multirow{2}{*}{ Region } & \multicolumn{2}{|c|}{ Yes } & \multicolumn{2}{c|}{ No } & \multicolumn{2}{c|}{ NS } \\
\cline { 2 - 7 } & $\#$ & \% & $\#$ & \% & $\#$ & \% \\
\hline Eastern & 12 & 16.2 & 60 & 81.1 & 2 & 2.7 \\
\hline Central & 25 & 11.6 & 190 & 88.0 & 1 & 0.5 \\
\hline Western & 9 & 20.5 & 35 & 79.5 & - & - \\
\hline $\begin{array}{l}\text { Mid- } \\
\text { western }\end{array}$ & 9 & 18.4 & 40 & 81.6 & - & - \\
\hline Far-western & 4 & 23.5 & 13 & 76.5 & - & - \\
\hline Total & 59 & 14.8 & 338 & 84.5 & 3 & 0.8 \\
\hline
\end{tabular}

The data presented in the table no. 1 showed that in total $14.8 \%$ reported 'yes' whereas $84.5 \%$ said 'no' regarding the influence of the advertisement of OTC medicines in their personal buying behaviors.

Region wise data showed that respondents of Far-western region were highly influenced (23.5\%) due to the OTC advertisement whereas, the respondents of Central region were least influenced, 11.6\%. $20.5 \%$ respondents of Western region reported 'yes' followed by $18.4 \%$ from the Midwestern region, and $16.2 \%$ from Eastern region to the influence of advertisement.

The response of people showed that advertisement of OTC medicines could inform about the product and its indications but was not so effective to change the buying behavior of the people. Less than $25 \%$ people only had reported that they were influenced from the advertisement of OTC medicines. A previous study stated that advertising is simply way to sell a product -to announce what products are available, who made them, and where you go to buy (Moriarty, Mitchell, \& Wells, 2009, p. 53). It might be the reasons that advertisements had not much effect on buying behavior of consumers in Nepalese context. Study of The World Self-Medication Industry showed the similar finding with this study. The World Self-Medication Industry found that while self- 
medication usage levels (as opposed to brand choice) does not seem to be influenced by advertising, it appears that education, healthcare awareness and an understanding of trends in more advanced societies do play a role. In India (1995), it was shown that literate people were $76 \%$ more likely to self-medicate than illiterate people (The World Self-Medication Industry, 2007).

\section{Effect of advertisement of OTC medicines on people perception}

The study tried to measure the positive and negative effect of advertisement of medicines on perception of the customers. The response tabulated in the table no. 2 shows that in total $46 \%$ reported that there was positive effect of advertisement whereas $16 \%$ reported the negative effect. Table 2: Effect of advertisement of OTC medicines on people perception

\begin{tabular}{|l|c|c|c|c|c|c|c|c|}
\hline \multirow{2}{*}{\multicolumn{1}{c|}{ Region }} & \multicolumn{2}{|c|}{ Positive } & \multicolumn{2}{c|}{ Negative } & \multicolumn{2}{c|}{ NS } & \multicolumn{2}{c|}{ DK } \\
\cline { 2 - 10 } & $\#$ & \% & $\#$ & \% & $\#$ & \% & $\#$ & \% \\
\hline Eastern & 29 & 39.2 & 13 & 17.6 & 2 & 2.7 & 30 & 40.5 \\
\hline Central & 93 & 43.1 & 38 & 17.6 & 4 & 1.9 & 81 & 37.5 \\
\hline Western & 26 & 59.1 & 4 & 9.1 & - & - & 14 & 31.8 \\
\hline Mid-western & 26 & 53.1 & 7 & 14.3 & 1 & 2.0 & 15 & 30.6 \\
\hline Far-western & 10 & 58.8 & 2 & 11.8 & - & - & 5 & 29.4 \\
\hline Total & 184 & 46.0 & 64 & 16.0 & 7 & 1.8 & 145 & 36.2 \\
\hline
\end{tabular}

Region wise, 39.2\% of Eastern region respondents reported the positive effect of advertisement of OTC medicines followed by $43.1 \%$ from Central region, 59.1\% from the Western region, $53.1 \%$ from the Mid-western region and 58.8\% from the Far-western region.

Nearly $50 \%$ of the study samples responded positively about the effect of advertisement of OTC medicines. It can be accepted that 'information is power' so it is good to say that advertisement of any kinds of medicine or health related services can be supportive to take the decision for customers. OTC medicines are popular in Nepal but formal advertisement of OTC medicines is lacking.

\section{CONCLUSION}

The analysis of data shows that advertisement of OTC medicines has positive effect on the awareness level of the people regarding OTC medicines but there wasn't a positive correlation of advertisement to change in the buying behavior of OTC medicines. In Nepalese context, very limited numbers of advertisement of OTC medicines can be seen on the online and print media. On the one hand, very limited people have easy access of television or newspaper/magazines. It may be the reason advertisements are less effective. It is found that only $32 \%$ respondents purchased OTC medicine after viewing the advertisement whereas, only $14.8 \%$ reported that they 
ISSN: 2362-1303 (Paper) | elSSN: 2362-1311(Online)

JOURNAL OF ADVANCED ACADEMIC RESEARCH (JAAR)

Jan 2016

were influenced by the advertisement of OTC medicines. Very few people trusted in the advertisement done through television or newspaper. It was observed that majority of people trusted in the recommendation of medical hall than other media.

\section{REFERENCES}

Bhangale, V. (8-10 April, 2007). OTC Marketing of Drugs. International Marketing Conference on Marketing \& Society (pp. 397-402). Mumbai, India: IIMK.

Dhar, D. ( 2011, June). ADVERTISING AND ITS SOCIAL RESPONSIBILITY. Global Media Journal - Indian Edition/Summer Issue, 1-6.

Khan, M. Y., Gupta, P., Goswami, D. D., Bihari, B., \& Verma, V. K. (2013). A Review on Marketing of OTC Drugs. Asian J. Res. Pharm. Sci., Vol. 3(Issue 2), Pg 72-78.

Moriarty, S., Mitchell, N., \& Wells, W. (2009). Advertising: Principles \& Practice. New Jersey: Pearson.

ORGANISATION OF PHARMACEUTICAL PRODUCERS OF INDIA. (2011). India OTC Pharma Profile 2011. Mumbai 400 013, INDIA: ORGANISATION OF PHARMACEUTICAL PRODUCERS OF INDIA/ Website: www.indiaoppi.com.

R. Bakhshi, I. Q. (2010). Effect of Advertisements on Awareness and Knowledge of Urban Homemakers. Stud Home Comm Sci, 4(3), 185-189.

Sawant, M. R. (2012, Nov. - Dec.). Impact of Advertising on Brand Awareness and Consumer Preference (With Special Reference to Men`S Wear). IOSR Journal of Business and Management (IOSR-JBM), Volume 5(Issue 6), PP 54-61.

The World Self-Medication Industry. (2007). Responsible Self-Care and Self-Medication: A Worldwide Review of Consumer Surveys. Keynes and France: The World SelfMedication Industry. 
ISSN: 2362-1303 (Paper) | elSSN: 2362-1311(Online)

JOURNAL OF ADVANCED ACADEMIC RESEARCH (JAAR)

Jan 2016 